\title{
Verification and analysis of a climate simulation of temperature and pressure fields over Norway and Svalbard
}

\author{
Inger Hanssen-Bauer*, Eirik Førland \\ Norwegian Meteorological Institute, PO Box 43, Blindern, 0313 Oslo, Norway
}

\begin{abstract}
The monthly mean $2 \mathrm{~m}$ temperature and sea-level pressure (SLP) fields from the most recent integration (GSDIO) with the Max Planck Institute's global coupled climate model ECHAM4/OPYC3 are compared to historical data over Norway including Svalbard. For temperature, observations from selected stations are directly compared to values at grid points nearby. For SLP, modelled and observed gridded fields over the area $20^{\circ} \mathrm{W}-40^{\circ} \mathrm{E}, 50-85^{\circ} \mathrm{N}$ are compared by means of empirical orthogonal function (EOF) analysis. Finally, the connections between SLP and temperature over Norway are deduced for both historical data and results from the GSDIO integration and then compared to each other. The GSDIO 'control climate' grid point temperatures over Norway are in most cases found to be realistic, whenever it is possible to find stations with similar altitude and distance from the coast. The GSDIO 'future climate' indicates an annual mean warming of 0.2 to $0.5^{\circ} \mathrm{C}$ decade $^{-1}$ on the Norwegian mainland, and $0.8^{\circ} \mathrm{C}_{\text {decade }}^{-1}$ at the Svalbard grid point up to 2050. The strongest warming is simulated in winter, in the inland, and at high latitudes. The GSDIO 'control climate' SLP gradients imply on average westerly winds over Norway that are too weak. The GSDIO 'future climate', however, indicates an increase in the westerly wind component. Observations after 1960 show an increase in the westerly field of the same magnitude as in the GSDIO results during the same period. The observed connections between atmospheric circulation and temperatures in Norway are satisfactorily reproduced in the GSDIO integration, especially in winter. The winter warming in the GSDIO integration may partly be explained by the increase in the westerly wind component. On the Norwegian mainland, a linear regression model based on atmospheric circulation indices accounts for $1 / 3$ to $2 / 3$ of the 'scenario' warming in January. In July, the linear regression model does not account for any warming at all. The warming which is not accounted for by the linear regression model may be caused by non-linear processes (e.g. air-sea-ice interactions) or directly connected to changes in the climate forcing.
\end{abstract}

KEY WORDS: Climate model validation - Air temperature - Sea level pressure - Temperaturecirculation $\cdot$ Links $\cdot$ Regional scenarios

\section{INTRODUCTION}

The quality of future climate scenarios based upon atmosphere-ocean general circulation model (AOGCM) integrations depends strongly on the model's ability to realistically reproduce the largescale fields of meteorological variables. Improved scenarios on a regional or local scale may be achieved by

*E-mail: i.hanssen-bauer@dnmi.no empirical or dynamical downscaling techniques (e.g Murphy 1999), but only if the large-scale fields that are used as predictors or boundary conditions are realistic. It is thus crucial to validate the large-scale fields produced by the AOGCM integrations against observations, and to compare the relative merits of downscaled and raw AOGCM output (Wilby et al. 1999).

The 'GSDIO' integration (a transient integration including greenhouse gases, tropospheric ozone, and direct as well as indirect sulphur aerosol forcing) with the Max Planck Institute's AOGCM ECHAM4/OPYC3 


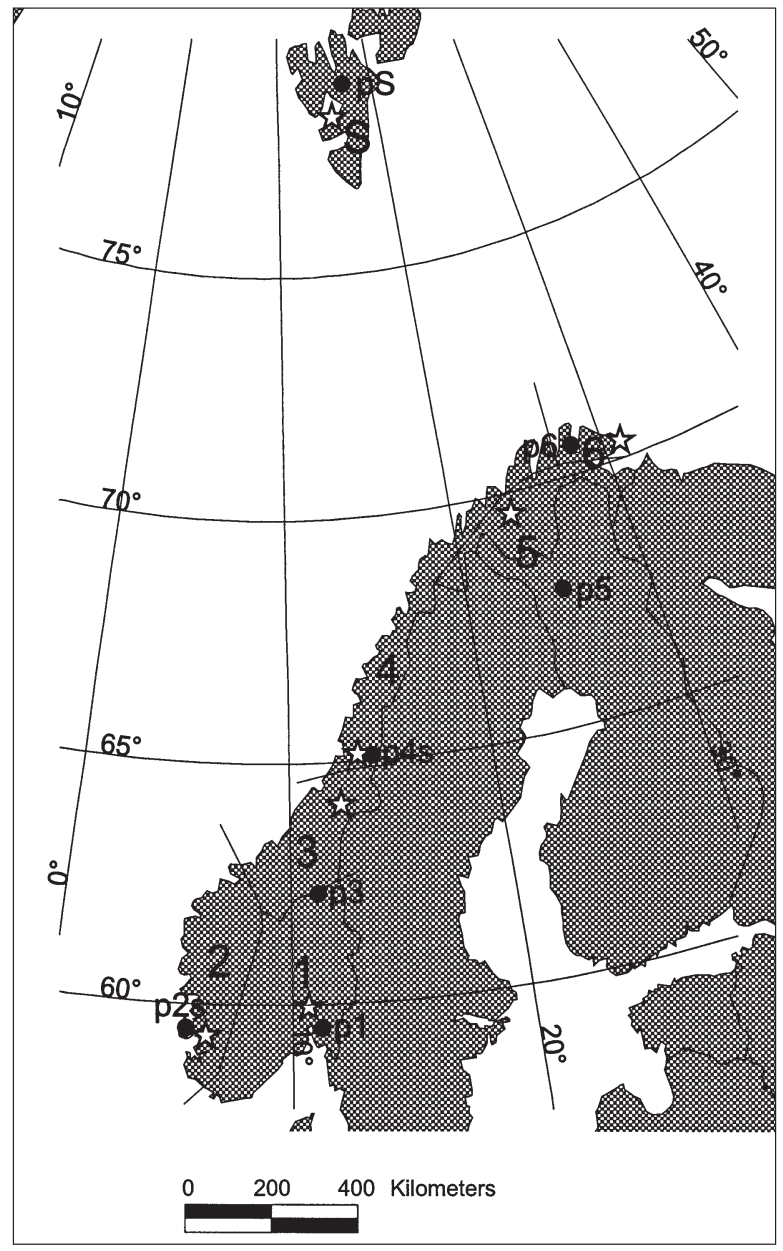

Fig. 1. Temperature regions 1 to 6 , grid points $(\bullet)$ and stations (访) used in the temperature analyses

(Roeckner et al. 1996, 1998, 1999) is presently used as a basis for downscaling of future climate in Norway, including Svalbard (Iversen et al. 1997). Machenhauer et al. (1998) validated a number of different climate simulations over Europe, including 3 simulations with the ECHAM4/OPYC3: One simulation of 'present-day climate' (no changes in greenhouse gases) and 2 greenhouse-gas (GHG) simulations (including increasing GHG concentrations), one with historical GHG levels and one with projected levels. Benestad et al. (1999) validated monthly fields from the ECHAM4/ OPYC3 'present-day climate' simulation globally, but with a focus on Scandinavia. Christensen et al. (1998) nested the ECHAM4/OPYC3 present-day climate into very high-resolution climate models over Scandinavia and found close agreement between modelled and observed temperature climatology, except in certain areas in the north with few observations. Murphy (2000) stressed the importance of validating and improving correspondence between AOGCM model results and observed predictor/predictand relationships. In the present paper, results from the GSDIO integration (Roeckner et al. 1999) will be evaluated over Norway. The aim of the paper is to study how well the GSDIO integration reproduces the observed largescale atmospheric circulation, air temperatures, and especially the observed connections between the 2 quantities over Norway on a monthly basis. The study also includes a comparison between the GSDIO control climate and future climate in these areas. The identified links between temperatures and atmospheric circulation make it possible to estimate to what extent the simulated warming is directly caused by changes in the atmospheric circulation.

The data and methods used in the present study are presented in Section 2. In Section 3 the grid point temperatures from the GSDIO integration are compared to observations. In Section 4 sea-level pressure (SLP) fields from observations and the GSDIO integration are compared. In Section 5 we investigate whether the GSDIO integration reproduces the observed connection between atmospheric circulation and air temperatures in winter and summer, and estimates are made about how much of the simulated temperature increase may be attributed simply to systematic changes of the SLP field.

\section{DATA AND METHODS}

Using a combination of principal component analysis and cluster analysis (Singleton \& Spackman 1984) of 55 Norwegian time series, Hanssen-Bauer \& Nordli (1998) concluded that the temperature variation on the Norwegian mainland during the last $100 \mathrm{yr}$ is described fairly well by standardized monthly series from 6 'temperature regions' (Fig. 1). These regions are not characterized by internally uniform temperature, but rather by high correlation between temperature observations from different stations within the region. For the validation of the $2 \mathrm{~m}$ monthly mean air temperature from the GSDIO integration with the ECHAM4/OPYC3, 1 grid point was selected to represent each of the 7 temperature regions ( 6 for the Norwegian mainland and 1 for Svalbard, Fig. 1). The grid points are numbered according to the region they represent, while the grid point at Svalbard is denoted by ' $\mathrm{S}$ '. For the evaluation of how realistic the simulated grid point temperature is (Section 3), monthly means from 7 Norwegian stations (Fig. 1, Table 1) were considered. There are no decisive conclusions as to whether AOGCM grid point temperatures should be compared to area-averaged observations or directly with local values (Skelly \& Henderson-Sellers 1996, Huth et al. 2000). However, when comparing grid point temperatures and observa- 
tions, one should bear in mind that AOGCM output in general cannot be used directly on the local scale of single grid points or below. Neither topography nor a number of the processes that affect climate are resolved on these scales in the AOGCMs. Thus, the stations chosen for the present comparison are not necessarily located as close as possible to the selected grid points. An effort was made to find within the region each grid point represents a station with similar altitude and distance to the coast as the grid point in the model topography. The evaluation was accomplished by comparing 30 yr averages and standard deviations of monthly mean temperatures.

For comparing SLP fields (Section 4), modelled and observed monthly means from the same grid-net within the area $20^{\circ} \mathrm{W}-40^{\circ} \mathrm{E}, 50-85^{\circ} \mathrm{N}$ were applied (Fig. 2). The SLP observations were taken from the UK Meteorological Office (UKMO). 'The common EOF method' (EOF: empirical orthogonal function; Barnett 1999) was applied to observations during the period 1901-1997 and model results from the GSDIO integration during the period 1871-2050. When applying this method in the way described by Benestad (1999), the scores (amplitude functions) deduced from the model and the observations are associated with the same set of EOFs. In the present study, the observed and modelled SLP fields were combined without removing the mean values of each set first, as a main purpose of the present analysis is to compare observations and model and reveal systematic differences.

For studying temperature trends and connections between atmospheric circulation and temperature (Section 5), standardized time series for the 6 regions shown in Fig. 1 (Hanssen-Bauer \& Nordli 1998) were used, while Svalbard was represented by the standardized series from Svalbard Airport. To represent the temperature in the GSDIO integration, standardized time series were calculated for the temperature grid points (Fig. 1), using the 1961-1990 monthly averages and the respective standard deviations. Connections between the time series and the SLP field were established by multiple regression analysis between

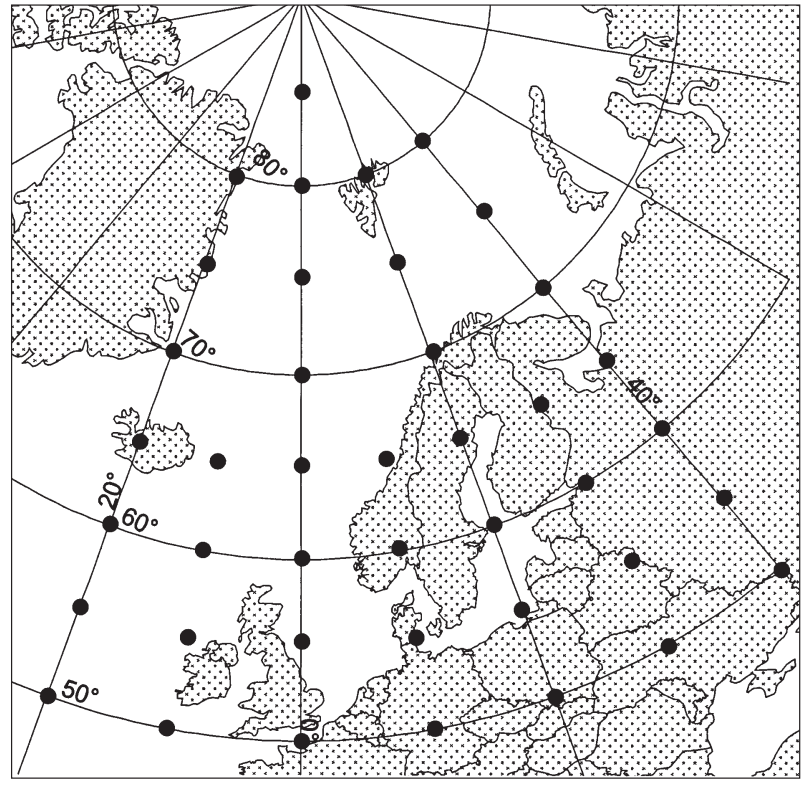

Fig. 2. Grid points used for the sea-level pressure (SLP) analyses

monthly temperature anomalies and the amplitude functions of the first common EOFs, as described by Hanssen-Bauer \& Førland (2000). In order to exclude components that did not significantly affect the temperature climate, stepwise regression was applied with a significance level of 0.15 as the condition for entry of new components into the models.

\section{TEMPERATURE VALIDATION}

In the present study, $30 \mathrm{yr}$ averages and standard deviations of monthly temperature means were compared for the grid points and stations (Table 1). Modelled (GSDIO) monthly temperature averages and standard deviations from different $30 \mathrm{yr}$ periods (not shown) revealed that while the $30 \mathrm{yr}$ averages before 1990 were rather stable for a given grid point, this was

Table 1. Geographical coordinates and height above sea level (m) for model grid points and for stations

\begin{tabular}{|c|c|c|c|c|c|c|c|}
\hline $\begin{array}{l}\text { Grid point } \\
\text { ID }\end{array}$ & $\begin{array}{l}\text { Latitude } \\
\left({ }^{\circ} \mathrm{N}\right)\end{array}$ & $\begin{array}{l}\text { Longitude } \\
\left({ }^{\circ} \mathrm{E}\right)\end{array}$ & $\begin{array}{l}\text { Altitude } \\
(\mathrm{m})\end{array}$ & Station & $\begin{array}{l}\text { Latitude } \\
\left({ }^{\circ} \mathrm{N}\right)\end{array}$ & $\begin{array}{c}\text { Longitude } \\
\left({ }^{\circ} \mathrm{E}\right)\end{array}$ & $\begin{array}{l}\text { Altitude } \\
\text { (m) }\end{array}$ \\
\hline $\mathrm{p} 1$ & 59.5 & 11.2 & 327 & Tryvann & 59.99 & 10.69 & 528 \\
\hline p2 & 59.5 & 5.6 & 252 & Ulladal-F. & 59.38 & 6.45 & 382 \\
\hline p3 & 62.3 & 11.2 & 501 & Kjøbli & 64.16 & 12.48 & 195 \\
\hline $\mathrm{p} 4$ & 65.1 & 14.1 & 433 & Majavatn & 65.18 & 13.42 & 339 \\
\hline p5 & 67.8 & 25.3 & 360 & Suolovuopmi & 69.59 & 23.53 & 374 \\
\hline p6 & 70.6 & 28.1 & 126 & Vardø & 70.37 & 31.08 & 14 \\
\hline $\mathrm{pS}$ & 78.9 & 16.9 & 106 & Svalbard Airport & 78.27 & 15.48 & 28 \\
\hline
\end{tabular}


a)

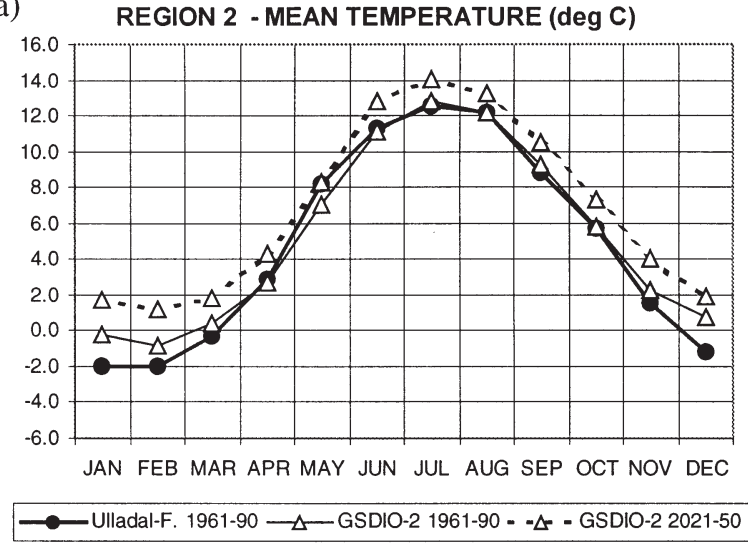

b)

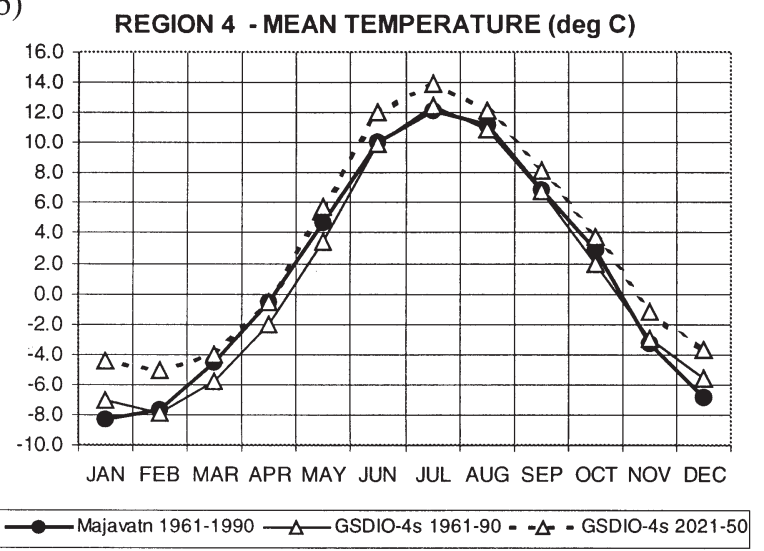

c)

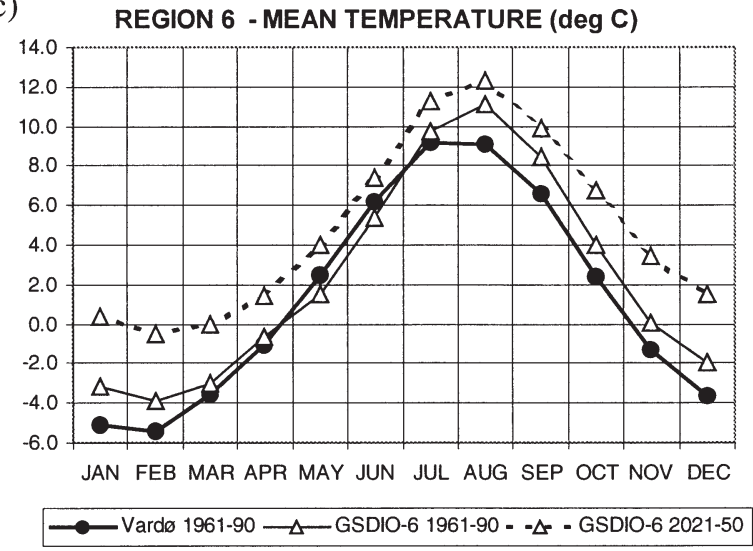

d)

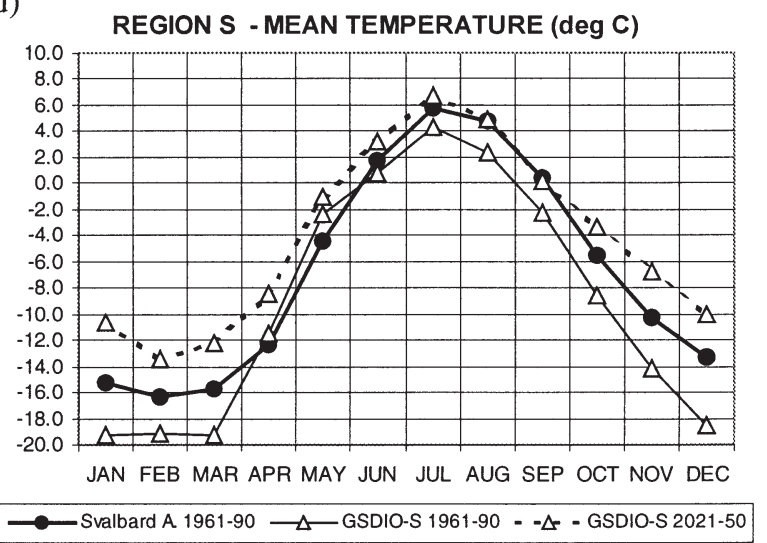

Fig. 3. Observed and modelled (GSDIO) monthly mean temperatures at selected grid points and stations in the temperature regions 2, 4, 6 and S. (๑) Values calculated from observations during the period 1961-1990. $(\Delta)$ Values calculated from the model: (-) based on model results for the period 1961-1990, (- - ) based on the period 2021-2050 (future scenario)

not generally true for the standard deviations. Especially, the standard deviation at grid point p6 for January during the period 1931-1960 was twice as high as for the other $30 \mathrm{yr}$ periods. This was caused by extremely low temperatures in this area during 2 winters in the 1930s, probably because the GSDIO integration produced sea ice too far south and west in the Barents Sea during these winters. For the following comparisons of modelled and observed temperatures, results from the period 1961-1990 are used.

Temperature averages and standard deviations at all grid points and stations in Table 1 have been presented by Hanssen-Bauer (2000); Fig. 3 shows only the averages from regions 2, 4, 6 and $\mathrm{S}$. The difference between grid point temperatures and observations at nearby stations seldom exceeds $1^{\circ} \mathrm{C}$, provided that stations are found in the same temperature region, at similar altitude, and approximately at the same distance from the coast. Some exceptions are found in winter at locations that are exposed for ground inversions (e.g. the valley station Ulladal-F., Fig. 3a). Exceptions are also found along the northern coast of Norway, where the model tends to give too high temperatures during autumn and winter (e.g. Fig. 3c). This is in accordance with the conclusions drawn by Machenhauer et al. (1998). They also concluded that the model tends to produce too cold spring seasons in southern and central parts of Norway, which is confirmed by the present study (e.g. Fig. 3a,b). The model's tendency to give too low spring temperatures and too high autumn temperatures might be connected to the modelling of sea-surface temperatures; however, further investigations of this are outside the scope of this paper. At Svalbard it was impossible to find grid points and stations with similar altitude and/or marine influence. The chosen grid point is too high (Table 1) and too far from the coast (Fig. 1). This may explain both that the grid point is colder than Svalbard Airport most of the year and also a certain phase shift in the annual temperature cycle (Fig. 3d).

The standard deviations of the monthly mean temperatures (not shown) also seem to be realistically 
EOF1

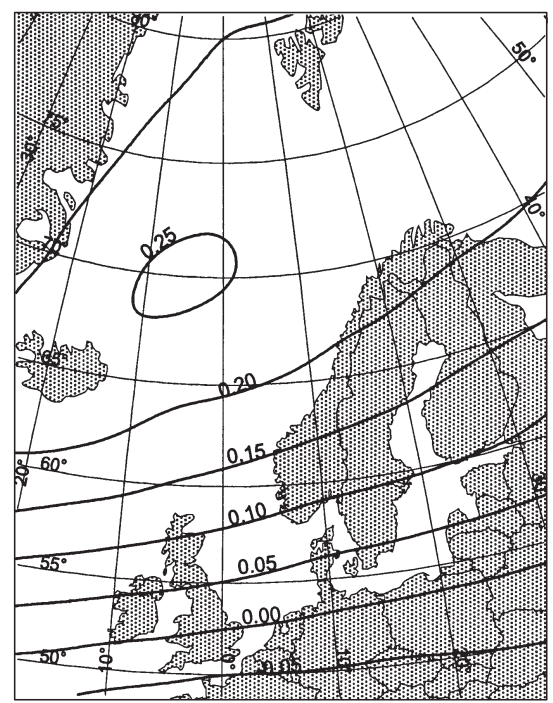

EOF2

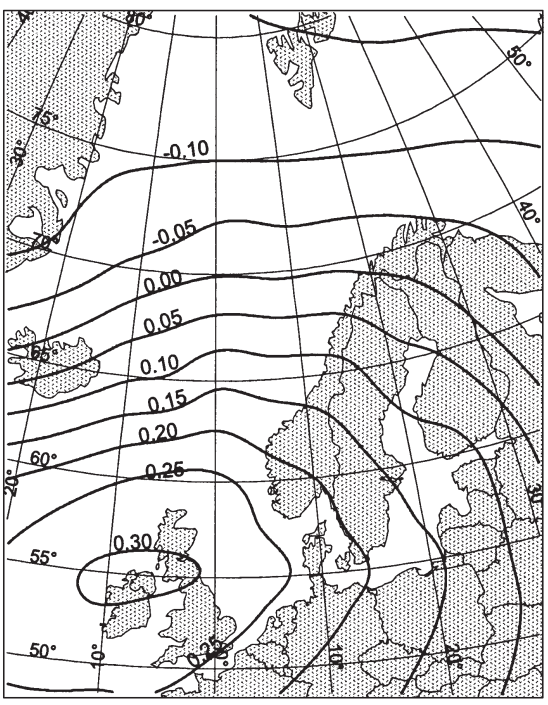

EOF3

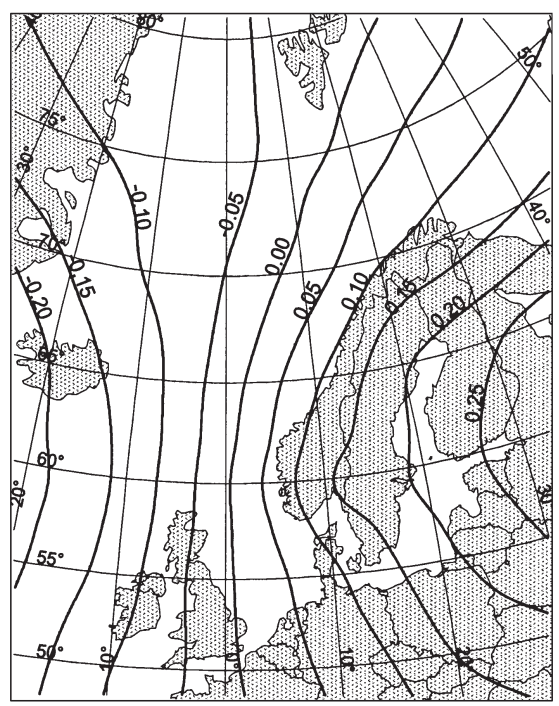

Fig. 4. Loadings for the 3 leading common EOFs deduced from monthly mean observed and modelled (GSDIO) SLP fields

modelled in most cases. The differences between model results and observations based upon the 1961-1990 monthly values may mainly be explained by differences concerning topography and marine influence. The standard deviation is generally larger in the inland than along the coast, and in winter and early spring it tends to be large at locations exposed for ground inversions. The model tends to overestimate the standard deviation in spring in regions where the temperature is underestimated, and vice versa in winter. On Svalbard, the modelled standard deviation is larger than observed most of the year, and especially during winter. This can be explained by the difference in distance from the coast between the grid point and Svalbard Airport.

Table 2. Eigenvalue of the covariance matrix in the common EOF analysis

\begin{tabular}{|c|c|c|c|c|}
\hline & Eigenvalue & Difference & Proportion & Cumulative \\
\hline EOF1 & 593.63 & 285.21 & 0.419 & 0.419 \\
\hline EOF2 & 308.42 & 40.31 & 0.218 & 0.637 \\
\hline EOF3 & 268.12 & 191.39 & 0.189 & 0.826 \\
\hline EOF4 & 76.73 & 11.87 & 0.054 & 0.880 \\
\hline EOF5 & 64.86 & 23.06 & 0.046 & 0.926 \\
\hline EOF6 & 41.81 & 29.16 & 0.030 & 0.956 \\
\hline EOF7 & 12.65 & 1.65 & 0.009 & 0.965 \\
\hline EOF8 & 11.00 & 2.09 & 0.008 & 0.973 \\
\hline EOF9 & 8.91 & 2.85 & 0.006 & 0.979 \\
\hline EOF10 & 6.07 & 2.29 & 0.004 & 0.983 \\
\hline EOF11 & 3.78 & 0.61 & 0.003 & 0.986 \\
\hline EOF12 & 3.17 & 0.81 & 0.002 & 0.988 \\
\hline
\end{tabular}

\section{SLP VALIDATION}

Eigenvalues and proportion of the variance accounted for by the 12 first common EOFs based upon observed and modelled SLP fields are given in Table 2. The spatial patterns associated with the 3 leading EOFs, which each account for more than $10 \%$ of the variance in the SLP field, are given in Fig. 4. The first 2 EOFs mainly include anomalies in the east-west component of the airflow over Norway. The first one (EOF1) shows a centre northeast of Iceland similar to the northern centre of the North Atlantic Oscillation (NAO). Negative EOF1 scores are associated with an intensified southwesterly to westerly airflow, in particular for the southern parts of Norway. Consequently, there is a strong negative correlation between the EOF1 scores and the NAO index. In January, February and March the correlation coefficients are $-0.84,-0.87$ and -0.82 , respectively. EOF2 has a centre over the British Isles. Positive scores for EOF2 are associated with an intensified northwesterly to westerly wind field over Norway. The third EOF mainly includes anomalies in the south-north component of the airflow over the country. Positive scores are associated with southerly wind anomalies.

An argument against using common EOFs has been that certain patterns may appear only in one of the included data sets, maybe even during a limited period. When comparing the standard deviations of the scores connected to the individual EOFs for different 30 yr periods of the observations and the model integration, however, we can see that there are no sys- 

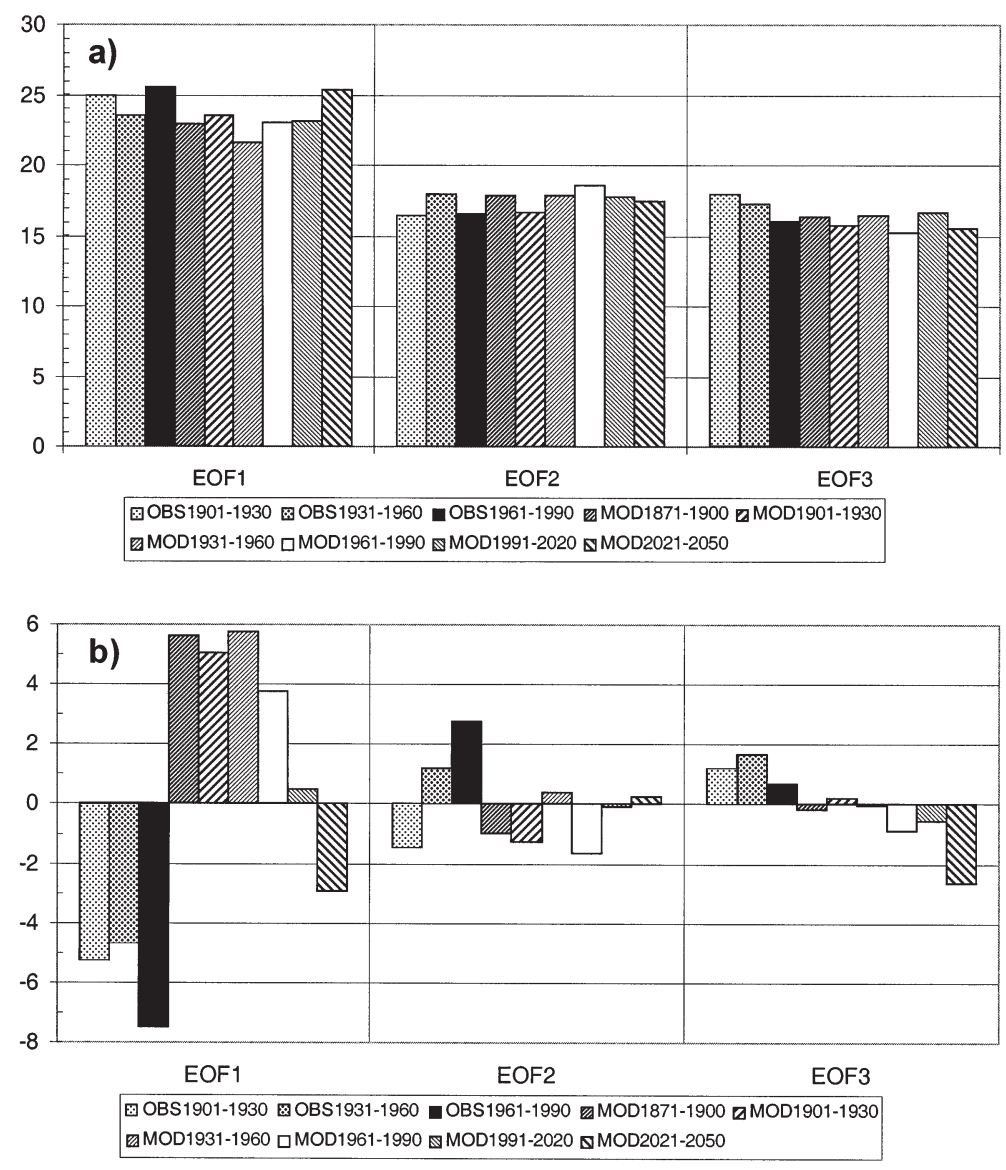

Fig. 5. (a) Standard deviations and (b) mean values for the scores connected to the 3 leading common EOFs deduced from the monthly mean SLP fields. Values are calculated for consecutive $30 \mathrm{yr}$ periods from observations and from the results of the GSDIO integration

tematic differences between observations and model results (Fig. 5a). The differences between different $30 \mathrm{yr}$ periods also seem to be random. This is true for the 12 leading EOFs, though only 3 are shown here.

Averaging the observed and modelled EOF scores over consecutive $30 \mathrm{yr}$ periods (Fig. $5 \mathrm{~b}$ ) shows that, although the variance associated with the field is realistic, there is a bias in the modelled SLP field. The bias is most pronounced for EOF1, while EOF2 and EOF3 show smaller and less systematic differences. The observed SLP field is on average associated with a negative score for EOF1, while the average score for the GSDIO integration is positive, indicating that the average westerly wind field over Norway produced by the GSDIO integration is somewhat too weak. Comparing the observed and GSDIO integrated average SLP fields during the period 1961-1990 confirms this (Fig. 6). A plot of the difference between these fields (not shown) reveals a gradient from 0 in southern Norway to $-5 \mathrm{hPa}$ at Svalbard. Benestad et al. (1999) demonstrated a similar bias in the SLP field produced by the 'GHG integration' with the same model (ECHAM4/OPYC3).

The GSDIO integration produces a gradual increase in the average westerly wind field over Norway during the period 1960-2050 compared to the preceding $30 \mathrm{yr}$ periods (Fig. $5 \mathrm{~b}$ ). This is in accordance with the conclusions drawn by Knippertz et al. (2000) concerning the GHG integration with ECHAM4/OPYC3 for the winter (December to February). Results from the Hadley Centre climate model, HadCM3, seem to be less conclusive concerning this, but at least 2 integrations (a $4 \times \mathrm{CO}_{2}$ experiment and one with a $2 \%$ increase in $\mathrm{CO}_{2}$ per year) indicate that the winter NAO tends to be shifted to the positive phase when the $\mathrm{CO}_{2}$ level is high (McDonald et al. 1999). It is thus suggested that the climate signal connected to the increased concentrations of GHG implies an increased average south-north pressure gradient over Norway. In addition, in observations we find a reduction (a more negative value) of the average EOF1 score from 1931-1960 to 1961-1990. This seems to support the model results. However, note that the bias in the scores of the first EOF still exceeds the modelled change. A question arises: When it is known that the modelled westerly wind field for the control period is on average too weak, is it reasonable to expect that the modelled strengthening of the westerlies is realistic? The question is highly relevant, as methods for creating climate change scenarios that are based directly on the differences between the model's control and future climate in principle are making such assumptions.

\section{CONNECTIONS BETWEEN SLP FIELD AND TEMPERATURE}

Zorita \& von Storch (1997) investigated the skills of the ECHAM1 and ECHAM3 models to reproduce the observed connection between the North Atlantic SLP field and winter temperatures in Scandinavia. In the following section the skill of the ECHAM4/OPYC3 GSDIO integration to reproduce the observed connections between the SLP field and temperatures in different parts of Norway will be investigated in more detail.

Stepwise regression analysis (see Section 2) was applied to connect the leading 12 common EOFs from the SLP field to standardized temperature series from the 6 Norwegian regions and Svalbard (Fig. 1). 

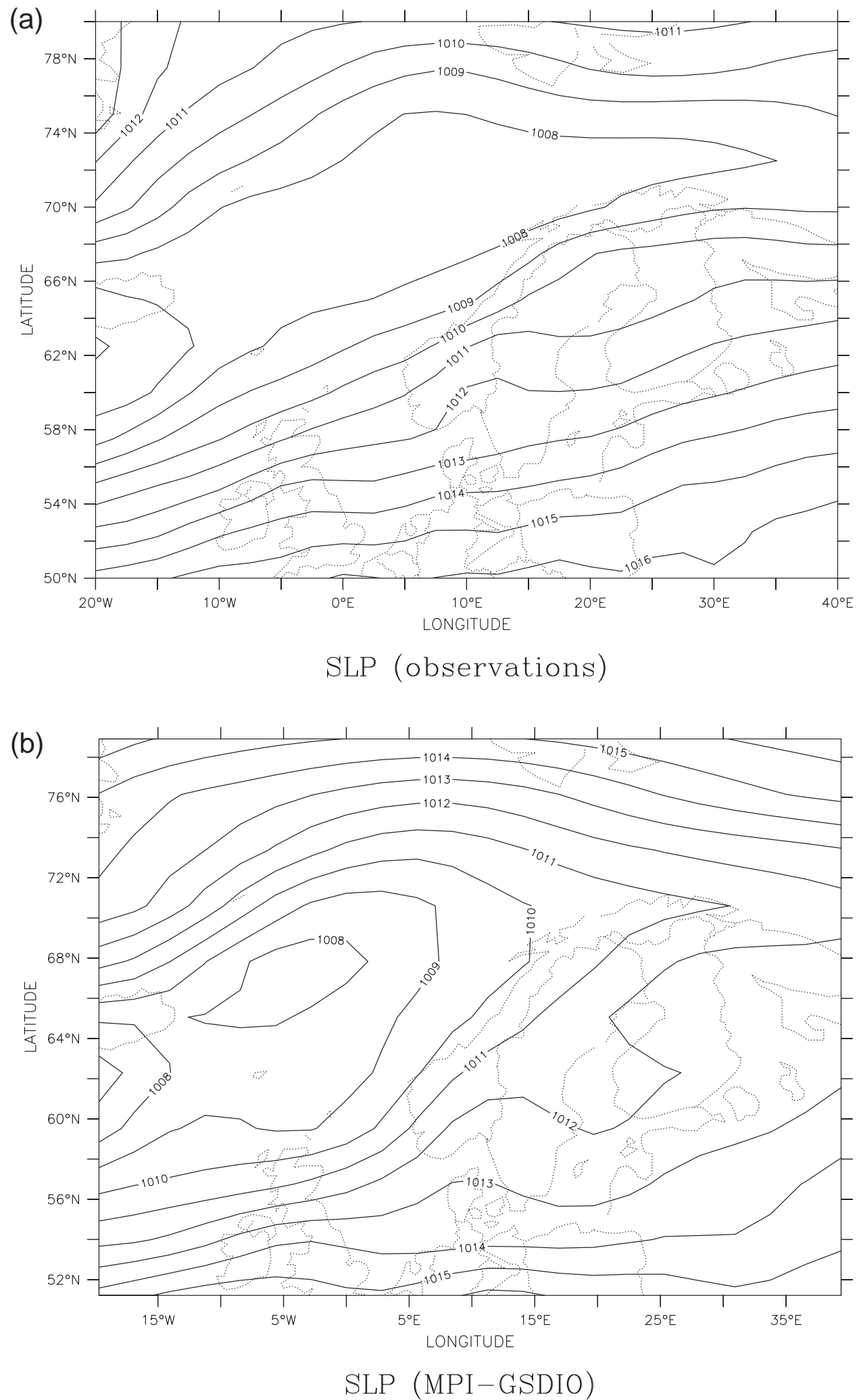

Fig. 6. Average SLP field (hPa) during the period 1961-1990 from (a) observations and (b) the GSDIO integration with ECHAM4/OPYC3 
Table 3. Correlation coefficients. (a) January and (b) July temperatures versus the SLP regression model

\begin{tabular}{|c|c|c|c|c|c|c|c|c|}
\hline Data & Period & $\begin{array}{l}\text { Region 1, } \\
\text { grid point } \\
\text { p1 }\end{array}$ & $\begin{array}{c}\text { Region } 2 \mathrm{n} \\
\text { grid point } \\
\text { p2 }\end{array}$ & $\begin{array}{c}\text { Region 3, } \\
\text { grid point } \\
\text { p3 }\end{array}$ & $\begin{array}{c}\text { Region } 4 \mathrm{~s} \\
\text { grid point } \\
\text { p4 }\end{array}$ & $\begin{array}{l}\text { Region 5, } \\
\text { grid point } \\
\text { p5 }\end{array}$ & $\begin{array}{c}\text { Region } 6 \\
\text { grid point } \\
\text { p6 }\end{array}$ & $\begin{array}{c}\text { Region S, } \\
\text { grid point } \\
\quad \text { pS }\end{array}$ \\
\hline \multicolumn{9}{|l|}{ (a) January } \\
\hline \multirow{2}{*}{ Observations } & $1901-1960$ & 0.83 & 0.85 & 0.84 & 0.84 & 0.79 & 0.65 & 0.78 \\
\hline & 1961-1997 & 0.86 & 0.86 & 0.84 & 0.88 & 0.87 & 0.63 & 0.62 \\
\hline \multirow[t]{6}{*}{ GSDIO } & $1871-1900$ & 0.86 & 0.82 & 0.82 & 0.78 & 0.75 & 0.64 & 0.55 \\
\hline & 1901-1930 & 0.87 & 0.89 & 0.88 & 0.79 & 0.74 & 0.52 & 0.73 \\
\hline & 1931-1960 & 0.71 & 0.69 & 0.80 & 0.68 & 0.55 & 0.21 & 0.46 \\
\hline & 1961-1990 & 0.85 & 0.82 & 0.86 & 0.77 & 0.68 & 0.50 & 0.75 \\
\hline & $1991-2020$ & 0.83 & 0.80 & 0.84 & 0.83 & 0.80 & 0.73 & 0.56 \\
\hline & $2021-2050$ & 0.78 & 0.82 & 0.85 & 0.77 & 0.71 & 0.75 & 0.64 \\
\hline \multicolumn{9}{|l|}{ (b) July } \\
\hline \multirow[t]{2}{*}{ Observations } & 1901-1960 & 0.82 & 0.81 & 0.82 & 0.84 & 0.84 & 0.75 & 0.66 \\
\hline & 1961-1997 & 0.78 & 0.79 & 0.78 & 0.77 & 0.76 & 0.61 & 0.59 \\
\hline \multirow[t]{6}{*}{ GSDIO } & $1871-1900$ & 0.64 & 0.59 & 0.71 & 0.72 & 0.80 & 0.54 & 0.60 \\
\hline & $1901-1930$ & 0.61 & 0.35 & 0.66 & 0.74 & 0.75 & 0.36 & 0.55 \\
\hline & $1931-1960$ & 0.56 & 0.64 & 0.65 & 0.57 & 0.70 & 0.30 & 0.37 \\
\hline & $1961-1990$ & 0.55 & 0.55 & 0.59 & 0.61 & 0.72 & 0.47 & 0.33 \\
\hline & $1991-2020$ & 0.63 & 0.58 & 0.72 & 0.68 & 0.75 & 0.56 & 0.58 \\
\hline & $2021-2050$ & 0.66 & 0.54 & 0.77 & 0.71 & 0.77 & 0.55 & 0.34 \\
\hline
\end{tabular}

Though the 12th common EOF accounts for a small amount of the variance in the SLP field (Table 2), it was included because it seems to be of importance for the temperature at Svalbard. Models were developed based upon observations during the period 1901-1960 (training period), for January and July (see Appendix 1). They were applied to SLP fields observed during the period 1961-1997 (validation period), and the SLP fields resulting from the GSDIO integration for the period 1871-2050. Correlation coefficients between observed regional temperatures and the results from the regression models were calculated for the training period and the validation period. Similarly, correlation coefficients were calculated between the standardized GSDIO grid point temperatures and results from the regression models for different $30 \mathrm{yr}$ periods. In January (Table 3a), the correlation coefficients for the GSDIO temperatures are, in most cases, similar to those for observed temperatures. Exceptions are found for the model period 1931-1960, during which period the correlation coefficients are lower, especially at the northern grid points. This is caused by the 2 winters during the 1930s with very low temperatures, when the sea-ice edge in the model probably was unrealistically far west and south (see Section 3). One may conclude that the GSDIO integration of ECHAM4/OPYC3 reproduces the observed connection between the atmospheric circulation and the Norwegian winter temperatures very well. In July (Table 3b) the correlation between temperatures and the results from the regression models are in most cases lower for the GSDIO series than for the observed series. Still, the correlation coefficients are clearly significant, revealing that the model reproduces some of the observed connections also during summer.

The correlation coefficients between the GSDIO temperatures and the results from the regression models vary substantially from one $30 \mathrm{yr}$ period to another (which is also the case for observed temperatures, although it is not shown here). The results in Table 3, however, show no systematic changes in the correlation coefficients. Thus the present results suggest that the connections between atmospheric circulation and temperatures in Norway are stable even under a changed climate.

An interesting question concerns whether, or to what degree, the temperature trends which the GSDIO-integration produce in Norway and at Svalbard may be attributed to the established connections between the SLP field and the temperature. The January and July series of temperatures from grid points 1 to 6 and $\mathrm{S}$ were compared to the regional series achieved by the regression model. The results from the regression model were multiplied by the 1961-1990 temperature standard deviation for the current grid point, in order to get the temperature increase in ${ }^{\circ} \mathrm{C}$. In January, the regression models gave temperature increases of between $1 / 3$ and $2 / 3$ of the warming predicted directly by the GSDIO integration for grid points at the Norwegian mainland (Fig. 7a). The temperature increase resulting from the regression models is mainly caused by the fact that an intensified southwesterly circulation during winter implies advection of relatively mild air masses to Norway. At Svalbard, the contribution from the regression model was, relatively 
a) Warming from $1961-90$ to $2021-50$, January

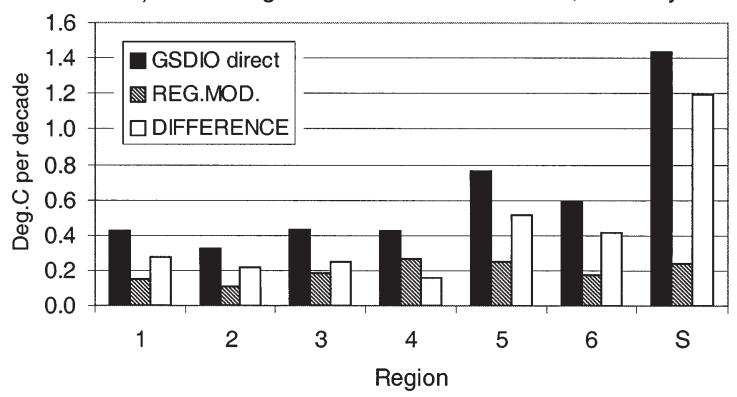

b) Warming from 1961-90 to 2021-50, July

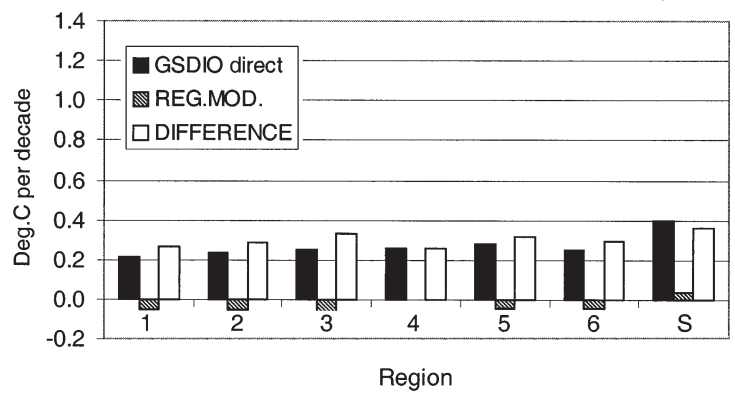

Fig. 7. Warming per decade in (a) January and (b) July in regions 1 to 6 in Norway and at Svalbard (S). Black bars show total warming according to the GSDIO integration with the ECHAM4/OPYC3 model. Hatched bars show warming (or cooling) which is accounted for by the changes in the SLP field. White bars show the residuals

speaking, much lower, probably because much of the warming in the Arctic during winter is connected to reduced sea ice cover, which leads to strong (and nonlinear) positive feedback mechanisms for the air temperature. In summer, the circulation based regression models give no contribution at all to the warming (Fig. 7b). One might expect this result, as an intensified westerly circulation in summer rather advects relatively chilly air masses to Norway. Thus, even though the warming predicted by the GSDIO integration is larger in January than in July, this is not in general true for the part of the warming which cannot be explained by the circulation based regression models.

\section{CONCLUSIONS}

The monthly grid point temperatures simulated in the GSDIO integration over Norway and Svalbard during the period 1871-1990 are in most cases found to be realistic, whenever it is possible to find stations with similar altitude and distance from the coast. A few outliers were found during winter and spring months at grid points close to the northern coast of Norway. These are probably caused by unrealistically harsh sea-ice conditions simulated during 2 winters in the 1930s. The model also tends to give slightly too cold spring seasons and/or too warm autumns at some locations. Apart from this, most differences between modelled and observed temperatures may be explained by differences between grid points and stations concerning altitude, the influence of marine air masses or local topography.

The GSDIO 'future climate' indicates an annual mean warming of 0.2 to $0.5^{\circ} \mathrm{C}$ decade $^{-1}$ at the grid points on the Norwegian mainland, and $0.8^{\circ} \mathrm{C}$ decade $^{-1}$ at the Svalbard grid point up to 2050. The warming is strongest in winter. It is larger inland than at the coast, and it increases with latitude.

The GSDIO 'control climate' SLP fields give on average a somewhat too weak westerly wind field over Norway. The GSDIO 'future climate' indicates an increase in the westerly wind component in this area. Observations after 1960 show an increase in the westerly field of the same magnitude as in the GSDIO results for the same period. An interesting question concerns whether the predicted continuing intensification of the westerlies is realistic, taking into account that the modelled westerlies are too weak in the 'control period'. In other words: Is it reasonable to suggest that the model bias is constant when the climate is changing? As far as we know, this assumption is implicit in most scenarios for climate change, though different methods exist for removing the bias (e.g. Huth \& Kysely 1999).

The observed connections between atmospheric circulation and temperatures in Norway and at Svalbard are satisfactorily reproduced in the GSDIO integration, especially in winter. The winter warming in the GSDIO integration may partly be explained by the increase in the westerly wind component. For the Norwegian mainland, a linear regression model based on atmospheric circulation indices accounts for $1 / 3$ to $2 / 3$ of the warming in January. In July, the linear regression model does not account for any warming at all. The reason for this is that an intensified westerly wind field is associated with marine air masses, which are relatively mild in winter but not in summer. The warming that is not accounted for by the linear regression model may be caused by non-linear processes (e.g. air-seaice interactions) or directly connected to changes in the climate forcing.

Acknowledgements. The present report is a result of the projects 'Regional climate development under global warming' (Reg Clim) (Iversen et al. 1997) and 'Long-term variations in atmospheric circulation and climate in the Norwegian Arctic', which are both supported by the Norwegian Research Council (NRC Contracts No. 120656/720 and 112890/720). The authors are indebted to R. Benestad, DNMI, for technical assistance and to 2 anonymous reviewers for constructive suggestions. 
Appendix 1. Models for calculating regional standardized monthly temperature series from the 12 first common EOFs based upon the monthly SLP field may be written: $T$ (standardized) $=a_{0}+a_{1} \times E O F 1+\ldots+a_{12} \times$ EOF12. The models were developed using data from the period 1900-1960. Stepwise regression was applied in order to exclude components without significant influence in the specific models. A significance level of 0.15 was used as condition for entry of new components into the models. Regression coefficients for January and July are given in the table. X: coefficients not included in the stepwise procedure

\begin{tabular}{|c|c|c|c|c|c|c|c|}
\hline $\begin{array}{l}\text { Regression } \\
\text { coefficients }\end{array}$ & 1 & 2 & 3 & $\begin{array}{c}\text { Region } \\
4\end{array}$ & 5 & 6 & $\mathrm{~S}$ \\
\hline \multicolumn{8}{|l|}{ January } \\
\hline$a_{0}$ & -0.60 & -0.81 & -0.83 & -0.88 & -0.36 & -0.57 & 0.01 \\
\hline$a_{1}$ & -0.0208 & -0.0234 & -0.0238 & -0.0233 & -0.0196 & -0.0191 & -0.0024 \\
\hline$a_{2}$ & $\mathrm{X}$ & X & 0.0086 & 0.0183 & 0.0163 & 0.0107 & 0.0043 \\
\hline$a_{3}$ & 0.0121 & 0.0174 & 0.0163 & 0.0343 & 0.0253 & 0.0292 & 0.0304 \\
\hline$a_{4}$ & 0.0272 & 0.0198 & 0.0160 & X & X & -0.0193 & X \\
\hline$a_{5}$ & 0.0295 & 0.0282 & 0.0325 & 0.0360 & 0.0225 & 0.0360 & -0.0433 \\
\hline$a_{6}$ & X & X & X & 0.0227 & 0.0275 & 0.0307 & 0.0369 \\
\hline$a_{7}$ & $\mathrm{X}$ & $\mathrm{X}$ & $\mathrm{X}$ & X & 0.0453 & X & X \\
\hline$a_{8}$ & 0.0294 & 0.0186 & $\mathrm{X}$ & -0.0490 & -0.0334 & $\mathrm{X}$ & $\mathrm{X}$ \\
\hline$a_{9}$ & -0.0369 & -0.0241 & -0.0485 & X & $\mathrm{X}$ & 0.0777 & -0.0438 \\
\hline$a_{10}$ & 0.0496 & 0.0539 & 0.0589 & 0.0649 & $\mathrm{X}$ & $\mathrm{X}$ & $\mathrm{X}$ \\
\hline$a_{11}$ & X & X & X & X & $\mathrm{X}$ & $\mathrm{X}$ & $\mathrm{X}$ \\
\hline$a_{12}$ & $\mathrm{X}$ & $\mathrm{X}$ & $\mathrm{X}$ & $\mathrm{X}$ & $\mathrm{X}$ & $\mathrm{X}$ & 0.0926 \\
\hline \multicolumn{8}{|l|}{ July } \\
\hline$a_{0}$ & -0.14 & 0.36 & 0.22 & 0.31 & 0.69 & 0.68 & 0.52 \\
\hline$a_{1}$ & 0.0324 & 0.0358 & 0.0470 & $\mathrm{X}$ & $\mathrm{X}$ & $\mathrm{X}$ & -0.0191 \\
\hline$a_{2}$ & X & -0.0363 & -0.0560 & -0.0629 & -0.0366 & -0.0182 & -0.0620 \\
\hline$a_{3}$ & 0.0462 & 0.0694 & 0.0802 & 0.0483 & 0.0584 & 0.0485 & $\mathrm{X}$ \\
\hline$a_{4}$ & -0.0973 & -0.1066 & -0.0816 & 0.0418 & 0.0797 & 0.0941 & 0.0362 \\
\hline$a_{5}$ & -0.0984 & -0.1019 & -0.1363 & -0.1172 & -0.1255 & -0.0625 & -0.0094 \\
\hline$a_{6}$ & $\mathrm{X}$ & -0.259 & $\mathrm{X}$ & $\mathrm{X}$ & $\mathrm{X}$ & 0.0796 & $\mathrm{X}$ \\
\hline$a_{7}$ & -0.0552 & X & X & $\mathrm{X}$ & $\mathrm{X}$ & -0.0506 & 0.0084 \\
\hline$a_{8}$ & -0.0943 & -0.0430 & -0.0513 & $\mathrm{X}$ & $\mathrm{X}$ & $\mathrm{X}$ & X \\
\hline$a_{9}$ & 0.1392 & 0.1728 & 0.1913 & $\mathrm{X}$ & -0.0394 & -0.1323 & $\mathrm{X}$ \\
\hline$a_{10}$ & $\mathrm{X}$ & X & X & $\mathrm{X}$ & $\mathrm{X}$ & $\mathrm{X}$ & $\mathrm{X}$ \\
\hline$a_{11}$ & $\mathrm{X}$ & 0.1989 & $\mathrm{X}$ & 0.0779 & 0.1376 & $\mathrm{X}$ & $\mathrm{X}$ \\
\hline$a_{12}$ & $\mathrm{X}$ & X & $\mathrm{X}$ & $\mathrm{X}$ & X & $\mathrm{X}$ & 0.1918 \\
\hline
\end{tabular}

\section{LITERATURE CITED}

Barnett TP (1999) Comparison of near-surface air temperature variability in 11 coupled climate models. J Clim 12: $511-518$

Benestad R (1999) Evaluation of the common EOF approach in linear empirical downscaling of future ECHAM4/ OPYC3 GSDIO climate scenarios. DNMI Report 35/99 KLIMA, Norwegian Meteorological Institute, Oslo

Benestad RI, Hanssen-Bauer I, Førland EJ, Tveito OE, Iden K (1999) Evaluation of monthly mean data fields from the ECHAM4/OPYC3 control integration. DNMI Report 14/99 KLIMA, Norwegian Meteorological Institute, Oslo

Christensen OB, Christensen JH, Machenhauer B, Botzet M (1998) Very high-resolution regional climate simulations over Scandinavia - present climate. J Clim 11: 3204-3229

Hanssen-Bauer I (2000) Verification and analysis of the ECHAM4/OPYC3 GSDIO temperature- and SLP-fields over Norway and Svalbard. DNMI report 06/00 KLIMA, Norwegian Meteorological Institute, Oslo

Hanssen-Bauer I, Førland EJ (2000) Temperature and precipitation variations in Norway and their links to atmospheric circulation. Int J Climatol 20:1693-1708

Hanssen-Bauer I, Nordli PØ (1998) Annual and seasonal temperature variations in Norway 1876-1997. DNMI Report 25/98 KLIMA, Norwegian Meteorological Institute, Oslo
Huth R, Kyselý J (1999) Constructing site-specific climate change scenarios on a monthly scale using statistical downscaling. Theor Appl Climatol 66:13-27

Huth R, Kyselý J, Pokorná L (2000) A GCM simulation of heat waves, dry spells, and their relationships to circulation. Clim Change 46:29-60

Iversen T, Førland EJ, Røed LP, Stordal F (1997) Regional climate under global warming. Project description. Norwegian Institute for Air Research (NILU), Kjeller

Knippertz P, Ulbrich U, Speth P (2000) Changing cyclones and surface wind speeds over the North Atlantic and Europe in a transient GHG experiment. Clim Res 15(2): 109-122

Machenhauer B, Windelband M, Botzet M, Christensen JH, Déqué M, Jones RG, Ruti PM, Visconti G (1998) Validation and analysis of regional present-day climate and climate change simulations over Europe. MPI Rep No. 275, Max Planck Institute for Meteorology, Hamburg

McDonald RE, Cresswell D, Senior CA (1999) Changes in storm tracks and the NAO in a warmer climate. In: Iversen T, Berg T (eds) Reg Clim General Tech Rep 2. Norwegian Institute for Air Research (NILU), Kjeller, p 11-20

Murphy J (1999) An evaluation of statistical and dynamical techniques for downscaling local climate. J Clim 12: 2256-2284 
Murphy J (2000) Predictions of climate change over Europe using statistical and dynamical downscaling techniques. Int J Climatol 20:489-501

Roeckner E, Arpe K, Bengtsson L, Christof M, Claussen M, Dümenil L, Esch M, Giorgetta M, Schlese U, Schulzweida U (1996) The atmospheric general circulation model ECHAM4: model description and simulation of presentday climate. MPI Rep No. 218, Max Planck Institute for Meteorology, Hamburg

Roeckner E, Bengtsson L, Feichter J, Lelieveld J, Rohde H (1998) Transient climate change simulations with a coupled atmosphere-ocean GCM including the tropospheric sulphur cycle. MPI Rep No. 266, Max-Planck-Institut für Meteorologie, Hamburg

Roeckner E, Bengtsson L, Feichter J, Lelieveld J, Rodhe H

Editorial responsibility: Hans von Storch, Geesthacht, Germany
(1999) Transient climate change simulations with a coupled atmosphere-ocean GCM including the tropospheric sulphur cycle. J Clim 12:3004-3032

Singleton F, Spackman EA (1984) Climatological network design. Meteorol Mag 113:77-89

Skelly WC, Henderson-Sellers A (1996) Grid box or grid point: what type of data do GCMs deliver to climate impact researchers? Int J Climatol 16:1079-1086

Wilby RL, Hay LE, Leavesley GH (1999) A comparison of downscaled and raw GCM output: implications for climate change scenarios in the San Juan River basin, Colorado. J Hydrol 225:67-71

Zorita E, von Storch H (1997) A survey of statistical downscaling techniques. GKSS97/E/20, GKSS Forschungs Zentrum, Geesthacht

Submitted: May 29, 2000; Accepted: September 6, 2000 Proofs received from author(s): February 26, 2001 